\title{
Role of polygenic hazard score in prostate-specific antigen (PSA) screening for prostate cancer
}

\author{
Ning Shao ${ }^{1,2}$, Yao Zhu ${ }^{1,2}$, Dingwei Ye ${ }^{1,2}$ \\ ${ }^{1}$ Department of Urology, Fudan University Shanghai Cancer Center, Shanghai 200032, China; ${ }^{2}$ Department of Oncology, Shanghai Medical College, \\ Fudan University, Shanghai 200032, China \\ Correspondence to: Yao Zhu; Dingwei Ye. Department of Urology, Fudan University Shanghai Cancer Center and Department of Oncology, Shanghai \\ Medical College, Fudan University, 270 Dong'an Road, Shanghai, 200032, China. Email: mailzhuyao@163.com; dwye.shca@gmail.com. \\ Comment on: Seibert TM, Fan CC, Wang Y, et al. Polygenic hazard score to guide screening for aggressive prostate cancer: development and \\ validation in large scale cohorts. BMJ 2018;360:j5757.
}

Submitted Jul 17, 2018. Accepted for publication Jul 26, 2018.

doi: $10.21037 /$ tcr.2018.07.22

View this article at: http://dx.doi.org/10.21037/tcr.2018.07.22

Prostate cancer (PCa) affects 161,360 people in the USA in 2017 and is responsible for nearly 26,730 deaths, accounting for $19 \%$ of all new cases and $8 \%$ of all cancer deaths in men (1). Previous studies suggested that prostate-specific antigen (PSA)-screening could reduce PCa mortality by $27 \%$ (2). However, screening could also bring over-diagnosis, subsequent over-treatment and a higher disease burden. Therefore, screening with PSA is controversial (3). As PCa is a heterogeneous disease, most patients have indolent cancers and some patients have potential lethal cancers. To avoid unnecessary screening, what kind of PCa patients can benefit from screening and whether to choose personalized screening approach have become a hot issue recently.

In view of PSA test being a poor predictor in distinguishing lethal cancers from indolent cancers, modified screening strategies for combining with other markers have been proposed. Previous studies suggested that targeting screening according to different risk groups may help to settle the problem. Due to the development of genome-wide association studies (GWAS), novel riskstratified screening based on polygenic risk may provide the potential to improve the efficacy of the PSA-screening (4).

Recently, a new article written by Seibert et al. was published on the British Medical fournal (BMF) (5). The objective of this study was to prove the hypothesis that polygenic risk could improve clinical decisions and guide PSA screening. They used a multiple institutions and large size design to develop a polygenic hazard score (PHS) for predicting age related risk of $\mathrm{PCa}$. The predictive value of
PHS was also tested in a validation set of 6,411 patients. The results indicated that PHS was a significant predictor of age related risk of PCa and associated with positive value of PSA test significantly. In other words, this study suggested that PHS was an indicator of the utility of PSA-screening and could inform both whether and when to order screening. In addition, the study also expressed that family history did not improve prediction over the PHS alone.

Over-diagnosis and over-treatment are complex issues, we cannot try to reduce the number of men invited to screening simply. Actually, most cancer patients eventually require treatment. As earlier treatment prevents development of metastatic cancer, reducing PSA-screening and biopsies may make patients with lethal PCa miss the chance of accepting proper treatment. Therefore, how to improve the balance between benefits and harms of PSA-screening is important. Orlando Burkhardt also agreed that the value of PSAscreening was higher among patients defined by particular factors, such as family history, ethnicity, age and polygenic risk (6-8). Any methods that could distinguish between indolent and potential lethal cancers should be welcomed.

This PHS, validated in an independent dataset, had shown accurate prediction of onset of aggressive PCa. Hence, the study provided an opportunity for PSA-screening informed by genetic risk. A previous study also insisted that targeting screening to men at higher polygenic risk could potentially solve the problem of over-diagnosis (9). All these results suggest that PHS to guide screening for aggressive PCa may be a better choice. Additionally, PHS 
may potentially help to guide early intervention in PCa and provide new sight on the mechanisms of PCa.

However, PHS to guide screening also faced some challenges. First, ethnicity in this study was limited to European ancestry. Validations of the PHS in other ethnic groups were needed. Dose the PHS have similar predictive value in Asians or Africans as in Europeans? Secondly, the cost of PHS is much higher than that of PSA test. If the use of PHS would increase the disease burden, it could block further popularization and application of PHS. Finally, the authors also suggested that they did not deal with the question: how the hazard score might compare to diagnostic tools (including risk calculators). In order to improve screening for lethal disease, any attempts to combine with variants to stratify individuals at risk are welcomed.

Although this genetic risk model might help guiding decisions about whether and when to screen for PCa, there is a long way to go. To improve the efficiency of the screening program, future studies with different ethnics and adequate data are warranted.

\section{Acknowledgments}

Funding: None.

\section{Footnote}

Provenance and Peer Review: This article was commissioned and reviewed by the Section Editor Peng Zhang (Department of Urology, Zhongnan Hospital of Wuhan University, Wuhan, China).

Conflicts of Interest: All authors have completed the ICMJE uniform disclosure form (available at http://dx.doi. org/10.21037/tcr.2018.07.22). The authors have no conflicts of interest to declare.

Ethical Statement: The authors are accountable for all aspects of the work in ensuring that questions related to the accuracy or integrity of any part of the work are appropriately investigated and resolved.

Cite this article as: Shao N, Zhu Y, Ye D. Role of polygenic hazard score in prostate-specific antigen (PSA) screening for prostate cancer. Transl Cancer Res 2018;7(Suppl 7):S743-S744. doi: $10.21037 /$ tcr.2018.07.22
Open Access Statement: This is an Open Access article distributed in accordance with the Creative Commons Attribution-NonCommercial-NoDerivs 4.0 International License (CC BY-NC-ND 4.0), which permits the noncommercial replication and distribution of the article with the strict proviso that no changes or edits are made and the original work is properly cited (including links to both the formal publication through the relevant DOI and the license). See: https://creativecommons.org/licenses/by-nc-nd/4.0/.

\section{References}

1. Siegel RL, Miller KD, Jemal A. Cancer Statistics, 2017. CA Cancer J Clin 2017;67:7-30.

2. Schröder FH, Hugosson J, Roobol MJ, et al. Screening and prostate cancer mortality: results of the European Randomised Study of Screening for Prostate Cancer (ERSPC) at 13 years of follow-up. Lancet 2014;384:2027-35.

3. Carlsson S, Leapman M, Carroll P, et al. Who and when should we screen for prostate cancer? Interviews with key opinion leaders. BMC Med 2015;13:288.

4. Eeles R, Goh C, Castro E, et al. The genetic epidemiology of prostate cancer and its clinical implications. Nat Rev Urol 2014;11:18-31.

5. Seibert TM, Fan CC, Wang Y, et al. Polygenic hazard score to guide screening for aggressive prostate cancer: development and validation in large scale cohorts. BMJ 2018;360:j5757.

6. Zheng SL, Sun J, Wiklund F, et al. Cumulative association of five genetic variants with prostate cancer. N Engl J Med 2008;358:910-9.

7. MacInnis RJ, Antoniou AC, Eeles RA, et al. Prostate cancer segregation analyses using 4390 families from UK and Australian population-based studies. Genet Epidemiol 2010;34:42-50.

8. Roobol MJ, Carlsson SV. Risk stratification in prostate cancer screening. Nat Rev Urol 2013;10:38-48.

9. Pashayan N, Duffy SW, Neal DE, et al. Implications of polygenic risk-stratified screening for prostate cancer on overdiagnosis. Genet Med 2015;17:789-95. 